\title{
A study of retinitis pigmentosa in the City of Birmingham. II Clinical and genetic heterogeneity
}

\author{
SARAH BUNDEY ANDS JAMES CREWS
}

From the Department of Clinical Genetics, Infant Development Unit, Birmingham Maternity Hospital, Birmingham B15 2TG; and the Birmingham and Midland Eye Hospital, Church Street, Birmingham B3 2NS.

SUMMARY This is a study of 138 index patients with retinitis pigmentosa (RP) and their families, in which the selection of index patients was solely on the basis of their residence in Birmingham. Clinical analysis showed that severe disease was as likely to indicate dominant or non-genetic RP as to indicate recessive disease, and that each of three genetic types of uncomplicated RP could probably be divided into two entities. Autosomal dominant RP accounted for at least $22 \%$ of index patients but this was likely to be an underestimate because of the low penetrance of the disease. Autosomal recessive disease accounted for not more than $10 \%$ of index patients and its rarity was indicated by a high consanguinity rate. Recognisable $X$ linked disease occurred in about $14 \%$ of index patients, a similar figure to other studies. The $37 \%$ of patients with uncomplicated RP and no obviously affected relative have either autosomal dominant RP or non-genetic RP; it is difficult to know the relative proportions of each.

The risks for descendants of patients with recessive disease are clear. The risks of symptomatic RP in the offspring of patients who do, or who might have, dominant RP range from 1 in 2 to 1 in 37 according to the family history and the severity of the RP.

Retinitis pigmentosa (RP) is a relatively common eye disorder, which may be inherited in three ways: autosomal dominant, autosomal recessive, and $\mathrm{X}$ linked recessive. There are no obvious clinical differences to distinguish between patients with the three types and so great reliance is placed on the family history when giving genetic counselling. However, most patients with RP have no symptomatic relatives and it is not clear how often such isolated patients have a genetic disorder and how often a non-genetic one. Sometimes examination of the female relatives of an isolated male patient may be helpful, since female heterozygotes for $\mathrm{X}$ linked RP can be clearly recognised by their patchy fundal abnormalities and by the fact that their retinal function disturbances are usually mild. ${ }^{1}$

The present study was aimed at providing data useful for genetic counselling. We wished to assess the relative frequencies of the different genetic types of RP and whether RP could be non-genetic. We also wished to assess to what extent autosomal dominant and $\mathrm{X}$ linked disease could be recognised by retinal function tests on asymptomatic persons.

Received for publication 30 May 1984. Accepted for publication 20 June 1984.
Most previous genetic studies of RP have analysed series of patients that have been selected because they have attended a specialist clinic $^{2}$ or because they belonged to a lay organisation which was likely to attract the young and severely affected sufferers. ${ }^{3}$ The present study, however, is based on a population of RP patients selected only because they lived in the City of Birmingham.

\section{Methods}

Patients were included in this genetic study if they had symptomatic retinitis pigmentosa in June 1978 and were living in the City of Birmingham. The methods of their ascertainment are described in the preceding paper. There was a total of 151 index patients and 63 secondary cases in the prevalence study, but 11 index patients could not be interviewed for the genetic study as three had died, four had moved away, and four refused a home visit. Two index patients gave a history of relatives with visual symptoms but these could not be verified as resulting from retinitis pigmentosa. These two families have therefore also been excluded.

This left 138 index patients from 131 families in 
the present genetic study; they were interviewed at home concerning the onset of visual symptoms, their rate of progression, and present severity. A family history was taken and relatives with visual symptoms were examined, or their medical records checked, or both. If both parents were asymptomatic we made an effort to examine them for evidence of RP. We also requested certain groups of relatives who might be helpful in elucidating the genetic type of RP to attend the Retina Department of the Birmingham and Midland Eye Hospital for retinal function tests: Goldmann perimetry, dark adaptometry, electroretinography (ERG), and electrooculography. These groups of relatives were the mothers, sisters, and daughters of severely affected male index patients who did not have an $\mathrm{X}$ linked pedigree, the parents of isolated cases, and the offspring (aged over 10 years) of patients with non-consanguineous parents.

Patients were separated into two main groups regarding severity of symptoms. The severe group consisted of patients who were registered blind or partially sighted by the age of 40 , or whose symptoms or retinal function tests at an earlier age were severe enough to expect that the patient would be registered by the age of 40 . These patients would not be expected to be able to continue their work after 40 although some would manage sheltered employment. The mild group consisted of those patients who had useful sight at the age of 40 or who were expected to have useful sight at that age and to be able to continue in their regular work.

No assumptions were made concerning genetic type and the severity of visual symptoms. The index patients were classified into genetic types as follows: autosomal dominant if an index patient had an affected parent or child and autosomal recessive if an index patient had consanguineous parents, or an affected sib and parents who were examined and found to be normal, or severe illness in one or more affected sibs and asymptomatic parents. The autosomal recessive syndromes of which retinitis pigmentosa is a part could be recognised by their distinctive clinical features, such as polydactyly, deafness, mental retardation, and kidney disease. $\mathrm{X}$ linked recessive disease was recognised if there was an $\mathrm{X}$ linked pedigree, or if a female relative had abnormalities of retinae or retinal function tests that were characteristic of the heterozygous state, or both. Isolated patients were those who had no history of disease in a relative and examination and retinal function tests revealed no abnormality in those relatives who were available for testing.

We wished to assess the fitness of the affected index patients, as indicated by the number of their living offspring. Because the index patients had a wide range of birth years (from 1904 to 1974), and because they included a number of different races, we considered it best policy to compare the numbers of their children with those of their unaffected sibs, who were similarly aged and came from a similar background. We did not consider that the presence of RP in a brother or sister would deter an asymptomatic person from having children.

\section{Results}

The index patients included in this genetic study consisted of 74 males and 64 females. They were mainly adults and their age distribution is given in table 3 of the preceding paper. They have been divided into different genetic groups as explained below and summarised in table 1 .

\section{AUTOSOMAL DOMINANT DISEASE}

There were 30 index patients from 27 families allocated to this category. Twenty-two had a symptomatic parent and 17 of these had affected relatives in at least three generations. Five patients had an affected parent only. Of the eight patients with asymptomatic parents, the parents of two could be examined and in each instance one was found tô have retinitis pigmentosa. Six patients were classio fied as having autosomal dominant disease becauseo of an affected child. Three of the children were symptomatic and three were asymptomatic. The pedigree of one of these index patients is shown in fig 1 to illustrate the difficulty of classifying index patients without examining their relatives.

The proportion of affected subjects among the offspring of the 24 index patients who had an affected parent was low, namely three out of 38

TABLE 1 Genetic categories of patients with retinitis pigmentosa who were living in Birmingham in 1978 (see text for reasons for classification).

\begin{tabular}{|c|c|c|c|}
\hline & \multirow[t]{2}{*}{ Index patients* } & \multicolumn{2}{|c|}{ Secondary cases } \\
\hline & & $\begin{array}{l}\text { With } \\
\text { symptoms }\end{array}$ & $\begin{array}{l}\text { Without } \\
\text { symptoms }\end{array}$ \\
\hline Autosomal dominant & $30(21 \cdot 7) \dagger$ & 33 & 10 \\
\hline Not classified $\ddagger$ & 5 & 0 & 0 \\
\hline \multicolumn{4}{|l|}{ Autosomal recessive } \\
\hline (a) No associated features & $14(10 \cdot 1)$ & 1 & 0 \\
\hline (b) Syndromes & $18(13 \cdot 0)$ & 13 & 2 \\
\hline \multicolumn{4}{|l|}{$X$ linked recessive } \\
\hline (a) Males & $19(13 \cdot 8)$ & 10 & 1 \\
\hline (b) Carrier females & 1 & 7 & 38 \\
\hline Isolated cases & $51(36 \cdot 9)$ & 0 & 0 \\
\hline \multicolumn{4}{|c|}{$\begin{array}{l}\text { * } 13 \text { index patients who were in the prevalence study were not included in the } \\
\text { genetic study (see text). } \\
\text { †Figures in parentheses give percentage of } 138 \text { index patients so classified } \\
\ddagger \text { Two or more mildly affected sibs whose parents were asymptomatic but no } \\
\text { examined. }\end{array}$} \\
\hline
\end{tabular}




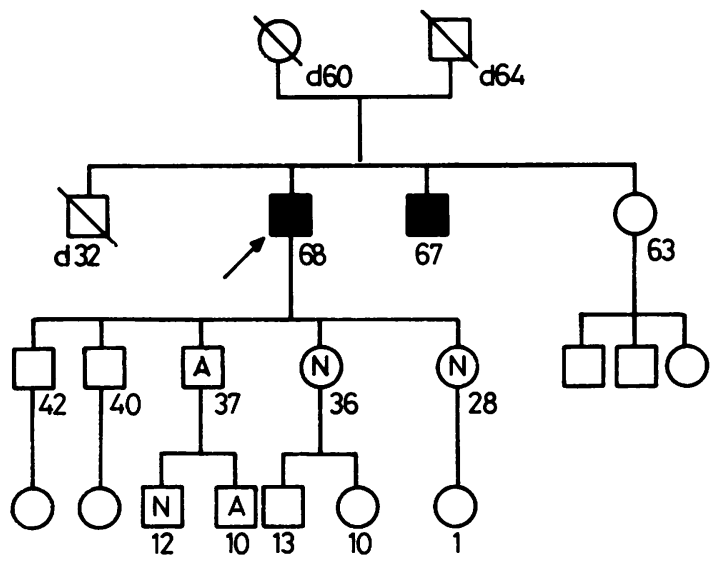

$\bigcirc \square$ No visual symptoms

Severely affected with RP

(N) N Normal on fundal examination and

(A) A Asymptomatic, but fundal examination

7 Proband

FIG 1 Pedigree of an index patient with autosomal dominant retinitis pigmentosa.

(table 2). This low figure occurred in spite of the fact that over half the offspring were examined and had tests of retinal function.

The age of onset distributions for the 30 patients with autosomal dominant disease is shown in fig 2 . However, the patients appeared to fall into two approximately equal groups, one where they had poor vision at the age of 40 and the other where they were expected to have useful sight at the age of 40 (table 3 ). To some extent the prognosis depended upon the age of onset, with 12 of 14 severely affected patients having onset before 20 years, whereas eight of 16 mildly affected patients had

TABLE 2 Penetrance of autosomal dominant $R P$ as shown by the numbers of affected offspring of the 24 index patients who had an affected parent.

\begin{tabular}{llll}
\hline $\begin{array}{l}\text { Age } \\
\text { group }\end{array}$ & \multicolumn{2}{l}{\begin{tabular}{l} 
Offspring without evidence of $R P$ \\
no symptoms \\
\cline { 2 - 4 } \\
but not tested
\end{tabular}} & $\begin{array}{l}\text { Fundal examination and } \\
\text { retinal function } \\
\text { tests normal }\end{array}$ \\
offspring \\
\hline Under 20 & 10 & 8 & $2^{*}$ \\
$20-29$ & 1 & 4 & 0 \\
30 and over & 5 & 7 & 1 \\
Total & 16 & 19 & 3 \\
\hline
\end{tabular}

*One of these had no symptoms but had an abnormally low ERG.
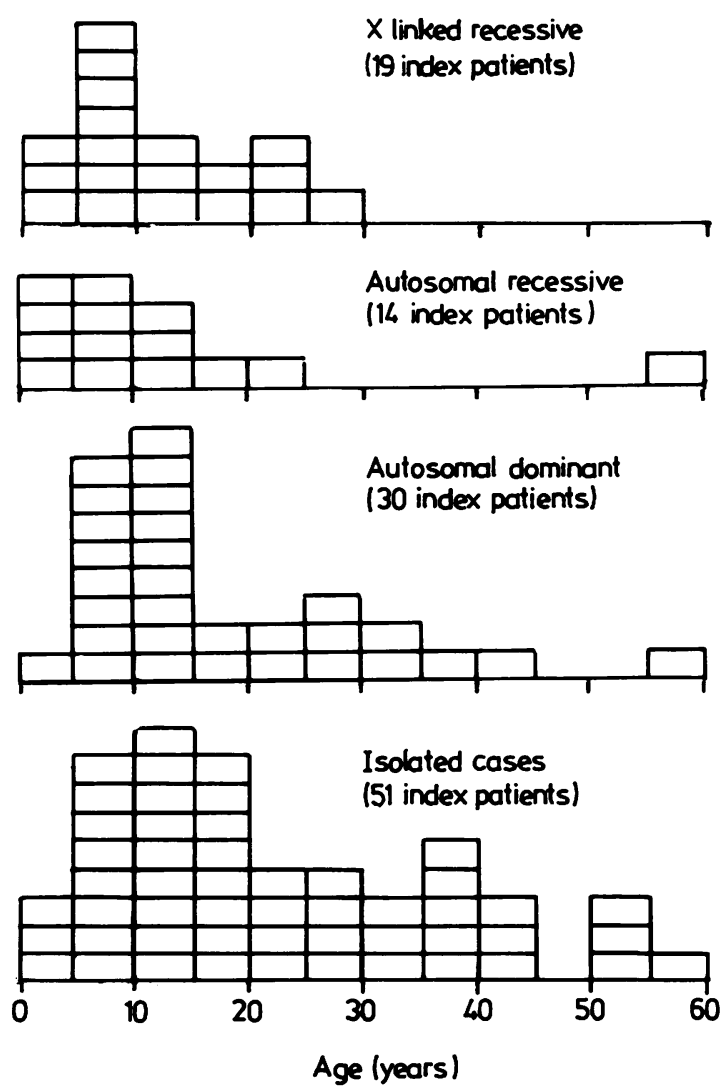

FIG 2 Distribution of age of onset of symptoms for $X$ linked recessive, simple autosomal recessive, autosomal dominant, and 'isolated' retinitis pigmentosa.

TABLE 3 The prognosis of index patients with $R P$ (actual numbers followed by proportion of total).

\begin{tabular}{lll}
\hline $\begin{array}{l}\text { Category of } \\
\text { index patient }\end{array}$ & $\begin{array}{l}\text { Registered as blind } \\
\text { or partially sighted } \\
\text { by age } 40 \\
\text { (or expected to be so) }\end{array}$ & $\begin{array}{l}\text { Having useful } \\
\text { sight at age 40, } \\
\text { or likely to } \\
\text { have }\end{array}$ \\
\hline $\begin{array}{l}\text { Autosomal dominant } \\
\begin{array}{l}\text { Uncomplicated autosomal } \\
\text { recessive }\end{array}\end{array}$ & $14(0.47)$ & $\begin{array}{r}16(0.53) \\
5(0.36)\end{array}$ \\
$\begin{array}{l}\text { X linked recessive } \\
\text { Isolated cases }\end{array}$ & $16(0.64)$ & $3(0.16)$ \\
\hline
\end{tabular}

onset at 20 years or later. Where information was available on affected relatives, they tended to resemble the index patient in severity. Nine affected relatives of severely affected index patients could be divided into four severely affected and five mildly affected, whereas seven affected relatives of mildly 
affected patients were all themselves mildly affected.

One index patient had external ophthalmoplegia but her affected father had no abnormality of eye movements. This patient has been classified as autosomal dominant RP and not under syndromes.

The fitness of index patients was not reduced (table 4).

AFFECTED SIBS, UNCLASSIFIABLE

There were five index patients who were mildly affected and who had mildly affected sibs. Their parents were asymptomatic but were not available for examination. Of the 15 offspring of index patients in this group, eight were examined and had normal retinal function tests. Because of the uncertainty as to whether these index patients had autosomal dominant or autosomal recessive disease, they have been omitted from the classification. There were no sibships in this group where all affected subjects were males.

\section{AUTOSOMAL RECESSIVERP WITH NO}

\section{ASSOCIATED FEATURES}

Included here are nine patients with consanguineous parents (five of British origin and four Muslims); four patients with severe disease in themselves and one or more sibs, and asymptomatic parents; and one parent with mild disease in himself and a sib, and parents who were both examined and found to be normal. If the four Muslims are excluded, the consanguinity rate among British index patients was $55 \%$ ( 5 out of 9 ) for those considered to have uncomplicated autosomal recessive disease, $22 \%$ (6 out of 27) for uncomplicated and syndromic autosomal recessive disease, and $5 \%(6$ out of 114$)$ for those in the whole study.

It is usual for autosomal recessive disease to produce symptoms before the age of 20 (fig 2) and so this should be taken into account when assessing the segregation ratios. The 14 index patients in this category had a total of 53 sibs; there was no

TABLE 4 Fitness* in index patients with retinitis pigmentosa compared to that of their unaffected sibs.

\begin{tabular}{lll}
\hline & Index patients & Unaffected sibs \\
\hline Autosomal dominant & $2.0(61 / 30)$ & $2 \cdot 0(160 / 81)$ \\
Autosomal recessive & $0.9(12 / 14)$ & $1.2(47 / 39)$ \\
X linked recessive & $1.5(30 / 20)$ & $1.8(73 / 41)$ \\
Unclassified & $3.0(15 / 5)$ & $1.3(49 / 37)$ \\
Isolated & $2.1(106 / 51)$ & $1.9(262 / 135)$ \\
Syndromes & $0.9(16 / 18)$ & $1.4(79 / 55)$ \\
Total & $1.7(240 / 138)$ & $1.7(670 / 388)$ \\
\hline
\end{tabular}

*As measured by number of children per person. The actual figures are given in parentheses. information on seven and, of the remainder, 37 were aged over 20 . Seven of these 37 had symptomatic RP giving an incidence of affected sibs of 1 in 5.2. If the four young Muslim families are excluded the proportion of affected sibs becomes 7 in 31 , or 1 in 4.5 .

One index patient in this group, who was born to parents who were double first cousins, had mild disease with onset of visual symptoms in her late $50 \mathrm{~s}$. If we are right to include her as having autosomal recessive disease, then she provides evidence of a distinct mild form of autosomal recessive RP. If we are incorrect in including her, then the proportion of affected sibs of the remaining 13 index patients becomes 7 in 31 .

However, even in the remaining 13 index patients there is a suggestion that autosomal recessive RP can be divided into severe and mild types. For, although the onset is fairly homogeneous (fig 2), nine patients were severely affected at the age of 40 (or expected to be so) while four were classified as mildly affected (table 3 ).

\section{AUTOSOMAL RECESSIVE SYNDROMES}

There were nine index patients with the Usher syndrome (deaf mutism and teenage onset of retinitis pigmentosa). No parents were consanguineous and eight of 48 sibs were similarly affected.

There were three patients with RP who acquired deafness in late childhood or adult life at a similar time to the onset of visual symptoms; one patient also totally lost her sense of smell. No set of parents was consanguineous and one out of eight sibs was similarly affected.

Five index patients had the Laurence-MoonBiedl-Bardet syndrome in which polydactyly was accompanied by obesity, mental retardation, and, in one of our families, renal tubular defects. No parents were consanguineous; six sibs out of 14 were similarly affected.

One index patient, born to parents who were first cousins once removed, had onset of RP and deafness in his teens and later developed a peripheral neuropathy. In spite of a clinical resemblance to Refsum syndrome he did not have an abnormality of phytanic acid metabolism.

X LINKED RECESSIVE RETINITIS PIGMENTOSA There were 19 male index patients in this category. Twelve were identified because they had an $X$ linked pedigree, with confirmation of RP in at least one other male relative. Seven patients were only identified because they had female relatives, who were available for fundal examination and retinal function tests, and in whom abnormalities characteristic of the heterozygous state were demonstrated. In these seven families there were three sibships in 
TABLE 5 Classification of severely affected male patients, who had non-consanguineous parents and no relative with visual symptoms apart from a brother (syndromes excluded).

\begin{tabular}{|c|c|c|c|c|c|}
\hline & \multicolumn{2}{|l|}{ Category known } & \multicolumn{3}{|l|}{ Classification impossible } \\
\hline & $\begin{array}{l}X \text { linked because } \\
\text { a female relative was } \\
\text { a carrier }\end{array}$ & $\begin{array}{l}\text { Autosomal dominant } \\
\text { because a child was } \\
\text { affected }\end{array}$ & $\begin{array}{l}\text { Not } X \text { linked as } \\
25 \text { year old daughter } \\
\text { not a carrier }\end{array}$ & $\begin{array}{l}\text { Mother not a } \\
\text { carrier for } X \text { linked } \\
R P\end{array}$ & $\begin{array}{l}\text { Female relatives over } \\
20 \text { not available }\end{array}$ \\
\hline $\begin{array}{l}\text { One or more brothers } \\
\text { affected ( } 4 \text { families) }\end{array}$ & 3 & 1 & 0 & 0 & 0 \\
\hline $\begin{array}{l}\text { Isolated index patient } \\
\text { (12) }\end{array}$ & 3 & 0 & 1 & 4 & 4 \\
\hline Total (16) & 6 & 1 & 1 & 4 & 4 \\
\hline
\end{tabular}

which brothers only were affected and four isolated male patients.

One family was ascertained through a carrier female who was registered blind and who had an X linked pedigree. This family was particularly interesting for it was an example of myopic degeneration occurring with RP as described by François and De Rouck. ${ }^{4}$ The affected males had both myopia and RP and the carrier females had a myopic degeneration which made it difficult to recognise the characteristic fundal appearance of a heterozygote and which led to blindness in early adult life.

Apart from this one family, the other families appeared to have a clinically homogeneous disease, with onset always by 30 years, and usually by 20 (fig 2 ), and with almost all patients being registered blind or partially sighted by the age of 40 (table 3 ). However, in spite of the consistent severity of the disease, there was no decreased fitness in patients with X linked RP when compared to their unaffected sibs (table 4).

In the twelve families with the usual form of $X$ linked RP, and with an $X$ linked pedigree, there were 12 obligatory heterozygotes who had fundal examination and retinal function tests. There were also further obligatory heterozygotes from $\mathrm{X}$ linked families outside Birmingham who were tested (Crews SJ, Bundey $S$, in preparation). Fundal examination and retinal function tests were abnormal in three-quarters of obligatory heterozygotes aged under 20 years, but after the age of 20 all obligatory heterozygotes showed an abnormality on at least one test. However, one woman of 31 had normal fundi although she did have abnormalities of retinal function, and two women of 22 and 46 had normal retinal function tests but abnormal fundi.

An attempt was made during the study to identify all severely affected male index patients who had X linked disease by examining their female relatives. However, reference to table 5 shows that in eight out of 15 instances no conclusions could be reached, as either no female relative over 20 years was available for tests, or the only relative available was a mother (and the patients might have been examples of new mutations). Five out of 15 such patients were assigned to the $\mathrm{X}$ linked category and one (fig 1) to the autosomal dominant category.

\section{ISOLATED CASES}

It was interesting that 76 patients (just over half the entire sample) had no relatives with visual symptoms. However, by the end of the study 25 could be assigned to one of the previously described genetic categories for the reasons listed in table 6, leaving 51 patients who remained as apparently isolated cases. These patients have been termed 'simplex' by other authors. ${ }^{2} 6$

These 51 patients consisted of 26 males and 25 females; 18 (10 males, eight females) were or were likely to be severely affected by the age of 40 and 33 were mildly affected. As with the dominant cases, there was an association between age of onset and prognosis, with all but one of the severely affected patients having onset before the age of 20 , whereas only one-third of the mildly affected patients did. The age of onset distribution (fig 2) was diffuse. There was a suggestion of bimodality for this group of patients, with one mode having onset before the age of 20 and the other between 35 and 45 years.

Many of the parents had died or were living outside Birmingham. However, 14 of 51 mothers and nine of 51 fathers were examined and found to be normal; 11 of those examined were parents of severely affected index patients and 12 were parents

TABLE 6 Allocation of 76 index patients who had no relatives with visual symptoms.

$\begin{array}{lr}\text { Numbers 'isolated' from pedigree } & 76 \\ \text { Assigned to AD category } & 2 \\ \text { (a) Asymptomatic affected parents } & 2 \\ \text { (b) Asymptomatic affected children } & 8 \\ \text { Assigned to AR category } & 9 \\ \text { (a) Consanguineous parents } & 4 \\ \text { (b) Recognition of a known syndrome } & 51 \\ \text { Assigned to XI category, because of tests on female relatives } & \\ \text { Number finally in 'isolated' category } & \end{array}$


TABLE 7 Distribution of types of retinitis pigmentosa, for both index and secondary cases, according to mode of ascertainment.

\begin{tabular}{|c|c|c|c|c|c|c|c|}
\hline & \multicolumn{7}{|c|}{ Percentage distribution of each type of $R P$, ascertained through: } \\
\hline & $\begin{array}{l}\text { All } \\
\text { sources }\end{array}$ & $\begin{array}{l}\text { Retina } \\
\text { Clinic }\end{array}$ & $\begin{array}{l}\text { Register } \\
\text { for p/s } \\
\text { or blind }\end{array}$ & $\begin{array}{l}R P \\
\text { society }\end{array}$ & $\begin{array}{l}\text { Genetic } \\
\text { clinic }\end{array}$ & $\begin{array}{l}\text { Other } \\
\text { sources* }\end{array}$ & $\begin{array}{l}\text { Through } \\
\text { family only }\end{array}$ \\
\hline Autosomal dominant & 32 & 26 & 28 & 17 & 25 & 47 & 47 \\
\hline Unclassifiedt & 3 & 4 & 3 & 4 & 0 & 0 & 0 \\
\hline \multicolumn{8}{|l|}{ Autosomal recessive } \\
\hline (a) Simple & 8 & 6 & 8 & 4 & 33 & 6 & 0 \\
\hline (b) Syndromic & 16 & 15 & 20 & 21 & 17 & 8 & 20 \\
\hline $\mathrm{X}$ linked recessive & 15 & 8 & 18 & 21 & 0 & 14 & 33 \\
\hline Isolated & 26 & 41 & 23 & 33 & 25 & 25 & 0 \\
\hline
\end{tabular}

${ }^{*}$ Referrals from general practitioners, opticians, and ophthalmologists.

tMild disease in one or more sibs, parents asymptomatic.

of mildly affected index patients. There was a total of 64 offspring aged over 10 years and of these 33 were both examined and tested and found to be without evidence of RP.

The fitness of these isolated patients was the same as that of their asymptomatic sibs (table 4). The mean parental ages at the birth of the isolated index patients was 28.2 years for 37 mothers and 30.7 years for 35 fathers, not significantly different from population figures.

The proportions of the different genetic types of RP vary somewhat according to the mode of ascertainment, as indicated in table 7 .

TABLE 8 Occurrence of visual symptoms before age 30 among offspring of 86 index patients with RP. (Index patients with recognisable recessive disease have been excluded.)

\begin{tabular}{|c|c|c|c|c|}
\hline & \multicolumn{4}{|c|}{ No of offspring } \\
\hline & $\begin{array}{l}\text { With no } \\
\text { symptoms } \\
\text { by age } 10\end{array}$ & $\begin{array}{l}\text { With no } \\
\text { symptoms } \\
\text { by age } 20\end{array}$ & $\begin{array}{l}\text { With no } \\
\text { symptoms } \\
\text { by age } 30\end{array}$ & $\begin{array}{l}\text { With symptoms } \\
\text { by age } 30\end{array}$ \\
\hline $\begin{array}{l}22 \text { index patients } \\
\text { with one } \\
\text { symptomatic } \\
\text { parent }\end{array}$ & 27 & 18 & 13 & $3^{*}$ \\
\hline $\begin{array}{l}21 \text { index patients } \\
\text { with severe } \\
\text { disease and } \\
\text { asymptomatic } \\
\text { parents }\end{array}$ & 19 & 12 & 6 & 2 \\
\hline $\begin{array}{l}43 \text { index patients } \\
\text { with mild } \\
\text { disease and } \\
\text { asymptomatic } \\
\text { parents }\end{array}$ & 88 & 70 & $36 \dagger$ & 1 \\
\hline
\end{tabular}

*One of these children was without symptoms when found to be affected at the age of 11 but we have assumed that he will develop symptoms before he is 30 . †This figure includes two patients who are affected but who have no symptoms.
EMPIRICAL RISKS FOR OFFSPRING FOR GENETIC COUNSELLING

In observing these risks, we have excluded those patients in the two autosomal recessive categories and the $\mathrm{X}$ linked category, for whom the risks for descendants are clear. The remaining 86 index patients have been divided into those with one symptomatic parent (22), those with severe disease and asymptomatic parents (21), and those with mild disease and asymptomatic parents (43). We thought it useful for genetic counselling to know the risks for offspring developing symptoms before the age of 30 and these are presented in table 8. In the first group, three of 16 offspring were symptomatic by the age of 30 , in the second group two of eight offspring had symptoms, and in the last group only one of 37 offspring had symptoms.

\section{Discussion}

Because the patients in this study were selected only by place of residence and not by severity of disease or the presence of similarly affected relatives, unbiased data are provided concerning clinical features and genetic types.

Some aspects of clinical features have been found to be unhelpful in assessing genetic type. Fig 2 shows that a patient with onset before the age of 20 is most likely to be isolated, and indeed is twice as likely to be isolated as to be either $\mathrm{X}$ linked or autosomal recessive. A patient with onset before the age of 10 has about equal chances of being isolated, recessive, or dominant. The numbers in table 3 show how a patient who is severely affected is equally likely to have $\mathrm{X}$ linked or dominant disease or to be an isolated case, with autosomal recessive inheritance being the least likely explanation for his/her severe symptoms. However, patients with onset after the 
age of 20 , or who are mildly affected at the age of 40 , are much more likely to be 'isolated' than to belong to a recognisable genetic category. Autosomal dominant disease is the next most likely possibility, whereas recessive varieties would be unlikely to account for such a clinical picture. The range of clinical manifestations in our families suggests that there are two autosomal dominant varieties, two autosomal recessive varieties, and two $\mathrm{X}$ linked varieties, of which one is readily recognised by the presence of myopic degeneration in female carriers. Arden et $a l^{7}$ have recently described electrophysiological evidence for two types of dominant RP.

There are certain conclusions to be made from our distribution of genetic types (table 1) before comparing it to other studies. Firstly, we consider that the 14 index patients whom we have assigned to the uncomplicated autosomal recessive category are likely to be the only patients with simple autosomal recessive disease in the whole study. We do not feel justified in including here the five patients with mild disease and affected sibs because dominant RP is frequently asymptomatic and retinal examination of the parents would be necessary before considering them healthy. We conclude that autosomal dominant inheritance is the most likely explanation for these five families. If we include some severely affected isolated cases in the autosomal recessive group, we will also add some unaffected sibs, lowering the segregation ratio even further; it is already less than the $1: 3$ to be expected with autosomal recessive inheritance. We consider that the fact that half the British patients with autosomal recessive $R P$ have consanguineous parents indicates that it is indeed a very rare disease.

Secondly, we consider that two generations of affected relatives are sufficient to categorise a patient as having autosomal dominant RP in view of the low penetrance of dominant RP in our study. Table 2 shows how we have identified only three affected offspring out of a total of 38 offspring of index patients with an affected parent, even after performing retinal function tests on more than half. Moreover, of the 30 patients classified as autosomal dominant, only 22 had a symptomatic parent. We know that two further parents are affected and it is likely that six from the other families are also affected. New dominant mutations are probably very rare in view of the unaltered fertility (table 4) and the mildness of the disease. It should also be noted that dominant RP may be very variable in its manifestation, as demonstrated by the family described in fig 1 .

The proportion of index patients with $\mathrm{X}$ linked disease $(13 \cdot 8 \%)$ is similar to that of other studies but it should be noted that seven of 19 male index patients did not have an $\mathrm{X}$ linked pedigree and were only identified because female relatives showed evidence of the carrier state. It is possible that there are one or two more isolated male index patients who have $X$ linked disease that we have been unable to recognise. However, the number is likely to be small because of the equal sex ratio of the isolated cases (unless non-genetic RP is commoner in females).

It is difficult to know how to explain the isolated cases of RP. Only a few are likely to have recessive disease for the reasons outlined above. An appreciable proportion is likely to have dominant disease with mild and asymptomatic affection in gene carrying relatives. In a study based on two retina clinics in Richmond, Virginia and Chicago, Illinois, ${ }^{5}$ the penetrance of autosomal dominant RP was found to be $40 \%$ after the age of 30 . Using this figure, Boughman and Fishman ${ }^{5}$ concluded that three-quarters of their isolated patients were in fact examples of autosomal dominant RP. From our study it is difficult to be certain about the proportion of isolated patients who have dominant disease, but the fact that large numbers of unaffected relatives were examined and found to be normal confirms the suggestion above ${ }^{5}$ that at least some isolated patients have a non-genetic disorder.

Because of the difficulty of distinguishing between non-genetic RP and autosomal dominant RP, both clinically and on family history, some empirical risks for symptoms occurring in offspring are given in table 8. These risks range from 1 in 4 to 1 in 37 . However, if a patient comes from a dominant family, with many affected members showing early onset of severe disease, then a 1 in 2 risk for offspring would be appropriate.

Our observations and conclusions are not the same as those of some other geneticists studying RP. The main differences between studies lie in the proportions attributed to autosomal dominant and autosomal recessive disease, and there are likely to be several reasons for these differences.

Amman et $^{8} \mathrm{l}^{8}$ reported the highest proportion of autosomal recessive disease: $90 \%$, of which $16 \%$ were syndromes. However, their experience of RP was of a serious disease, with patients ceasing to work between 30 and 40 years and becoming blind between 50 and 60 years. They also reported a high consanguinity rate of $26.7 \%$. These features make it likely that autosomal recessive RP is much commoner in Switzerland than elsewhere, perhaps due to an initial founder effect and subsequent inbreeding.

The next highest proportion of autosomal recessive disease $(41 \%)$ was reported by $\mathrm{Jay}^{2}$ in a population basically similar to that of Birmingham 
but ascertained through a genetic clinic. Her proportion of familial cases was much greater than in the present study, presumably because of this ascertainment. Table 7 shows that $33 \%$ of our cases ascertained through the genetic clinic would have been classified as autosomal recessive. However, in addition, Jay classified as autosomal recessive those cases with affected sibs and asymptomatic parents, and those isolated or simplex cases with severe disease. She was influenced by her experience of autosomal dominant disease having a penetrance of $90 \%$, whereas both the study of Boughman and Fishman ${ }^{5}$ and ours have demonstrated a penetrance very much lower than this. Similarly, the present study does not confirm that a severely affected index patient is most likely to have autosomal recessive disease.

$\mathrm{Hu},{ }^{6}$ in a study from Shanghai, reported a proportion of autosomal disease of $33 \%$, but he included families with one or more sibs affected with asymptomatic parents. It is interesting that he interpreted the high level of consanguinity of $15.9 \%$ as indicating that autosomal recessive RP may be caused by genes at many (between 11 and 41) loci. An alternative interpretation, favoured by us, is that the high consanguinity rate indicates that autosomal recessive RP is very rare, and probably overestimated in this series from China and others.

The study mentioned earlier, ${ }^{5}$ based on two retina clinics, yielded very similar results to the present study probably because both series of patients were largely unbiased with regard to family history or severity of disease. The present study also emphasises the importance of examining relatives, particularly parents.
We are grateful to the ophthalmologists and others who referred patients to us. We thank P Good and other members of the technical staff of the Retina Clinic of the Birmingham and Midland Eye Hospital for performing retinal function tests on numerous patients and their relatives. SB is indebted to the Research Committee of the West Midlands Regional Health Authority for financial support during the study. We also thank Mrs J Greenacre and Mrs J Cole for secretarial assistance.

\section{References}

${ }^{1}$ Bird AC. X-linked retinitis pigmentosa. Br J Ophthalmol 1975;59:177-99.

2 Jay M. On the heredity of retinitis pigmentosa. Br J Ophthalmol 1981;66:405-16.

3 Boughman JA, Conneally PM, Nance WE. Population genetic studies of retinitis pigmentosa. Am J Hum Genet 1980;32:22335.

${ }^{4}$ François J, De Rouck A. Sex-linked myopic chorio-retinal heredodegeneration. Am J Ophthalmol 1965;60:670-8.

5 Boughman JA, Fishman GA. A genetic analysis of retinitis pigmentosa. Br J Ophthalmol 1983;67:449-54.

$6 \mathrm{Hu}$ DN. Genetic aspects of retinitis pigmentosa in China. Am J Med Genet 1982;12:51-6.

7 Arden GB, Carter RM, Hogg CR, et al. Rod and cone activity in patients with dominantly inherited retinitis pigmentosa: comparisons between psychophysical and electroretinographic measurements. Br J Ophthalmol 1983;67:405-18.

8 Amman F, Klein D, Böhringer HR. Résultats préliminaires d'une enquête sur la fréquence et la distribution géographique des dégénérescences tapéto-rétiniennes en Suisse (étude de cinq cantons). J Genet Hum 1961;10:99-127.

Correspondence and requests for reprints to $\mathrm{Dr} S$ Bundey, Department of Clinical Genetics, Infant Development Unit, Birmingham Maternity Hospital, Birmingham B15 2TG. 